\title{
Lachen en treuren in de ethiek
}

\author{
Hub Zwart - Centrum voor Ethiek KUN
}

\section{Ethiek en humor}

Ethiek wordt eerder met het tragische dan met het komische in verband gebracht. En als het laatste al het geval is, dan is dat zelden als compliment bedoeld. Toen ik in 1988 op een vacature bij een ethisch onderzoeksinstituut solliciteerde, werd in een brochure over het betreffende instituut de filosoof Alasdair MacIntyre geciteerd. Een ethicus die zich met euthanasie en dergelijke wil inlaten, aldus MacIntyre, is "een komische figuur in een tragedie" waaruit hij maar beter kan verdwijnen (IGE 1986, p. 25). Dit citaat weerhield mij er niet van mijn sollicitatiebrief te schrijven. Want zijn het niet juist de komische figuren die in tragedies een kritische rol vervullen en op het beslissende moment de waarheid aan het licht brengen? De Griekse filosoof Isocrates stelde zelfs dat de waarheid alleen nog door komedianten wordt gesproken - een uitspraak die echter als verwijt aan het adres van zijn tijdgenoten was bedoeld (Foucault 1989, p. 39).

Bij nader inzien blijkt het verband tussen humor en ethiek oeroud. Misverstanden dienaangaande hangen vermoedelijk samen met het feit dat er sinds mensenheugenis twee ethische genres naast elkaar bestaan. Enerzijds de ethiek als een ernstig, academisch genre waarin doorgaans (in abstracte termen en op verheven toon) een klaagzang op de actualiteit ten beste wordt gegeven. Daarnaast is er echter een tweede genre, de traditie van het moralisme. De betreffende auteurs blinken uit in scherpzinnige observaties en geestige notities, aangeduid als 'maximen' of 'aforismen'. Bekende vertegenwoordigers zijn La Rochefoucauld, Lichtenberg en Nietzsche. In de middeleeuwen stond deze traditie te boek als $l a$ gaya sienza, de vrolijke wetenschap.

Het opvallende is dat beide genres teruggaan op een en dezelfde filosofische gestalte, namelijk
Socrates. De grondvester van de filosofie was een komiek, de Socratische dialoog moet tot de komische genres worden gerekend (al zijn vertalers nogal eens geneigd de tekst ernstiger, plechtstatiger en technischer te maken dan hij eigenlijk is). Neem bijvoorbeeld de sterfscène van Socrates in Phaedo. Hegel noemt deze scène echt tragisch (1971, p. 514, cf. p. 446) maar Socrates toont zich tot op het laatst een spotter. Zijn beroemde 'laatste woorden' spreken wat dat betreft boekdelen: "Crito, wij zijn Askleipios een haan schuldig". Askleipios was de Griekse god van de geneeskunst aan wie men destijds een haan offerde wanneer men van een ziekte was genezen. Socrates geeft met zijn kwinkslag te kennen het leven als een ziekte te beschouwen waarvan hij door de dood genezen wordt. De laatste taaldaad van deze aartskomiek is een grap uit een lange reeks waarmee hij de draak steekt met de tragische levenshouding van eerdere generaties, wier gehechtheid aan het leven immers de mogelijkheidsvoorwaarde voor het tragische was. Want alleen indien de held gehecht is aan het leven, kan de bereidheid om (met het oog op een nog hogere waarde) van het leven afstand te doen, als tragische keuze worden ervaren. Socrates daarentegen wil op geestige wijze benadrukken dat deze tragische gehechtheid aan het leven iets lachwekkends is. Phaedo laat zich dan ook lezen als één filosofische parodie op de tragische levenshouding der Grieken (Zwart, 1996).

\section{Wat is de mens? Het filosofische lachen}

$\mathrm{Na}$ Socrates' dood verschijnen diverse (elkaar beconcurrerende) filosofische scholen ten tonele die hem stuk voor stuk als hun leermeester beschouwen. Met name betreft het de Academische filosofie van Plato en de Cynische filosofie van 
Diogenes. Laatstgenoemde representeert het komische, zelfs schandalige aspect van Socrates' meesterlijke optreden. In vergelijking met zijn leermeester is de humor van Diogenes echter eerder praktisch en theatraal dan talig. Hij is de grootmeester van de filosofische practical joke. Zijn optreden kan als een komisch commentaar op het ernstige, academische vertoog van zijn tegenhanger Plato worden uitgelegd.

Een voorbeeld kan dit verduidelijken. Tijdens een college had Plato getracht een wetenschappelijke definitie van de mens te formuleren door hem als een 'veerloze tweevoeter' aan te duiden. Diogenes reageerde door zijn eigen studenten een geplukte haan voor te houden met de mededeling: 'Ziehier Plato's mens!', waarop Plato weer reageerde door 'met brede nagels' aan de definitie toe te voegen (Diogenes Laertius 1925/1979, 6:40). De komische techniek die Diogenes hanteert bestaat erin de woorden van de ander letterlijk te nemen. Zo wordt de lachwekkendheid en kwetsbaarheid van het schijnbaar ernstige onthuld. De (ernstige) gedachte die Diogenes op deze wijze tot uitdrukking wil brengen is (modern gezegd) dat een biologische definitie van de mens ten enenmale ontoereikend is om het eigenlijk menselijke aan te duiden, dat het eigenlijk menselijke niet in biologische kenmerken berust. Want de toevoeging 'met brede nagels' maakt de definitie er bepaald niet minder lachwekkend op.

Welhaast elke poging de mens louter biologisch te definiëren sorteert een dergelijk komisch effect. Aristoteles stelt bijvoorbeeld dat de mens niet alleen het enige dier is dat gekieteld kan worden (1937/1961, III x, 673a5-10), maar ook het enige dier zou zijn dat billen heeft (1937/1961, IV x, 689b0-35). En Hegel stelt ergens dat het oorlelletje als het kenmerkende van de mens kan worden aangemerkt, omdat het bij ieder ander dier ontbreekt. Hij voegt er echter onmiddellijk aan toe dat een dergelijke bepaling niet toereikend is om het wezenlijk menselijke aan te duiden - "Wenn's weiter nichts wäre, so könnte man z.B. als Merkmal des Menschen das
Ohrläppchen angeben, welches sonst kein Tier hat; da fühlt man aber zugleich, daß eine solche Bestimmung nicht hinreicht, das Wesentliche am Menschen zu erkennen" (1970, p. 19).

\section{Waar is de mens? Het filosofische treuren}

Dat Diogenes niet alleen kon lachen maar ook kon treuren, wordt door een andere anekdote onderstreept. Het verhaal ging dat hij op klaarlichte dag een lantaarn ontstak en door de stad zwierf, roepende: "Ik zoek een mens!". Achter dit ogenschijnlijk absurde optreden ging een ernstige boodschap schuil: de werkelijke, empirische mensen beantwoordden (toen al) niet aan het filosofische begrip van wat mensen eigenlijk zijn, aan de filosofische idee van mensheid als normatieve maatstaf.

Vele eeuwen later treffen we, in de geschriften van Nietzsche, een echo van deze scène aan. In De Vrolijke Wetenschap voert hij de "dwaze mens" ten tonele die midden op de dag een lantaarn ontsteekt, het marktplein betreedt en uitroept: "Ik zoek God", om daar vervolgens aan toe te voegen: God is dood, en wij hebben hem gedood. Alleen, we weten het nog niet, want sommige gebeurtenissen hebben tijd nodig om opgemerkt te worden (1967-77, 3, § 125). Beide voorbeelden geven aan dat het filosofische treuren betrekking heeft op een chronisch tekort in de werkelijke wereld. Het object dat aan een onontbeerlijke filosofische grondterm beantwoordt 'mens', 'God', et cetera - ontbreekt en laat enkel nog een schaduw achter.

Dezelfde structuur vinden we terug in een recenter voorbeeld van filosofisch treuren. In het eerste hoofdstuk van After Virtue nodigt de reeds genoemde Alasdair MacIntyre (1984) de lezer uit zich voor te stellen dat zich een ramp voltrokken heeft. Stel, zegt hij, dat de natuurwetenschappen zoals wij die kennen (met haar bibliotheken, laboratoria en dergelijke) door een anti-kennisbeweging zouden zijn vernietigd en dat vervolgens een nieuwe generatie zou proberen datgene 
wat verloren ging te restaureren. Van datgene wat eens een wetenschap was, zouden enkel nog fragmenten worden teruggevonden. Men zou eindeloos discussiëren over zwaartekracht, atomen en neuronen zonder echt te weten waarover men het had, zonder de betreffende termen in hun context te kunnen situeren. Allerlei wetenschappelijke termen zouden circuleren, maar de wetenschappelijke taal als geheel zou zich in een toestand van onophefbare wanorde bevinden.

Welnu, aldus MacIntyre, in een dergelijke toestand bevindt zich de hedendaagse ethiek. We bezigen nog steeds de sleuteltermen van weleer spreken over telos, vriendschap, wijsheid, enzovoort - maar we begrijpen ze niet langer. De ethiek staat in het teken van een onophefbaar tekort - het wezenlijke, het geheel waaraan de afzonderlijke termen hun betekenis ontlenen, is verloren gegaan. Er heeft zich een ramp voltrokken in onze morele cultuur, maar we weten niet precies wanneer, we hebben haar niet opgemerkt. Inderdaad, Nietzsche zei het al: sommige gebeurtenissen zijn zo rampzalig dat ze tijd nodig hebben om opgemerkt te worden.

Tot dusver heb ik het filosofische lachen en treuren aan de hand van een aantal min of meer bekende voorbeelden belicht. In de volgende paragrafen zal ik de vraag opwerpen of het, vanuit deze voorbeelden, mogelijk is tot een meer structurele bepaling te komen van wat wijsgerig lachen en treuren eigenlijk is, toegespitst op de ethiek. Om de structuur en functie van het filosofische lachen (voor zover het de ethiek betreft) nader te bepalen, zal ik mij in eerste instantie tot Kant, vervolgens tot Schopenhauer wenden.

\section{Wat is lachen?}

We lachen, aldus Kant, wanneer een hooggespannen verwachting plotseling opgaat in niets (1974, pp. 272 e.v., A 222 e.v.). Neem de grap van Diogenes. Met spanning luisteren we naar het betoog van een academische filosoof die op het punt staat een definitie van de mens te formuleren
- we houden de adem in... Een ogenschijnlijk ernstige definitie wordt gepresenteerd... En ineens verschijnt een filosofische clown ten tonele die (met één beweging) het fundamentele tekort, niet zozeer van deze ene definitie, maar van dit type discours als zodanig genadeloos blootlegt. Een heel discours blijkt op niets uit te lopen - het middenrif ontspant zich, wij lachen, aldus Kant.

Terwijl Kant de fysiologische aspecten van het fenomeen benadrukt, concentreert Schopenhauer zich op de psychologische dimensie. We lachen, aldus Schopenhauer, wanneer we plotseling een incongruentie vaststellen tussen het abstracte begrip en het empirische object dat we onder dit begrip subsumeren (1977, I $\S 13$, pp. 96 e.v.; II 8, pp. 109 e.v.). Dit is bijvoorbeeld het geval wanneer een bepaald object, waarvan we menen dat het aan het begrip beantwoordt, geconfronteerd wordt met een ander object, dat eveneens aan het begrip beantwoordt maar niettemin sterk van het eerste object verschilt. Opnieuw kan de grap van Diogenes dienst doen om dit te illustreren. Het object 'mens' lijkt aan het begrip 'veerloze tweevoeter' te beantwoorden. Wanneer echter blijkt dat dezelfde bepaling ook op een geplukte haan van toepassing is, wordt de incongruentie tussen begrip en object, dat wil zeggen het tekortschieten van de begrippelijke bepaling, plotseling manifest.

Het filosofische lachen heeft derhalve betrekking op de plotselinge gewaarwording van een begrippelijk tekort. Het betreft een gewaarwording die een radicaal nieuwe begrippelijke bepaling niet alleen noodzakelijk, maar vooral ook mogelijk maakt. Om de grap van Diogenes nogmaals als voorbeeld te hanteren: de poging het wezenlijk menselijke biologisch te bepalen loopt op niets uit. Het eigenlijk menselijke is precies datgene wat in deze begrippelijke bepaling ongezegd blijft en ontbreekt. Het filosofische lachen onthult een leegte (negatief geformuleerd), of schept een openheid (positief geformuleerd) waarin nieuwe discursieve mogelijkheden, nieuwe begrippelijke mogelijkheden kunnen verschijnen. 
Datgene wat een consistente en betekenisvolle eenheid leek - namelijk een biologisch discours dat een bepaald type taaluitingen over de mens genereerde - gaat op in het niets om plaats te maken voor nieuwe discursieve mogelijkheden.

In de volgende paragraaf zal ik betogen dat het filosofische treuren als de structurele tegenhanger van het filosofische lachen kan worden opgevat. Lachen en treuren zijn twee aan elkaar tegengestelde manieren om zich te verhouden tot een chronisch of structureel tekort in een gevestigd discours. Om de structuur en functie van het filosofische treuren nader te bepalen, wend ik mij tot Freud (1916/1946) en wel tot diens analyse van de melancholie.

\section{Wat is treuren?}

De melancholie, aldus Freud, is vergelijkbaar met de rouw in zoverre dat sprake is van objectverlies. De betrokkene kan het niet langer opbrengen zich voor de werkelijke wereld te interesseren, zijn aandacht aan de overgebleven objecten in die wereld te hechten. Het eigenaardige van de melancholie is echter dat we het verloren object niet kennen. We weten niet om welk object het gaat, en evenmin wanneer het precies verloren is gegaan. Niettemin staat de wereld als geheel in het teken (of in de schaduw) van een chronisch tekort. De werkelijkheid als geheel stelt in alle opzichten teleur. In feite, aldus Freud, is het echter niet de werkelijkheid, maar het Ik zelf dat leeg geworden is. Het denkbeeldige object waarvan het ontbreken een schaduw over de wereld werpt, heeft nooit werkelijk bestaan.

In de hedendaagse filosofie is de melancholie, met name waar het de ethiek betreft, sterk vertegenwoordigd. Het beroep op Freud zou echter kunnen suggereren dat ik voor een psychologiserende benadering van het fenomeen opteer, en dat is geenszins het geval. Wat ik aan Freud ontleen is een structurele bepaling van melancholie, die ik als discursief fenomeen wens op te vatten. Het gaat om een bepaalde discursieve structuur die in het hedendaagse filosofische spreken kan worden aangetroffen, ongeacht de feitelijke gemoedstoestand van de betrokken auteurs.

After Virtue van MacIntyre noemde ik al. Datgene wat verloren ging, blijkt het betekenisvolle geheel te zijn, de context waarop wij zouden kunnen vertrouwen maar die niet langer aanwezig blijkt. De wereld staat in het teken van een rampzalig verlies. Alles wat er gezegd wordt is zinloos, fragmentarisch en ontoereikend geworden. De talloze fragmenten lijken niet langer te beantwoorden aan iets algemeens. Het verlies lijkt bovendien onherstelbaar te zijn, de gebrokenheid laat zich niet meer ongedaan maken.

In de godsdienstfilosofische uiteenzettingen van Hegel treffen we vergelijkbare passages aan: God is een leeg concept, de staat is een nood- of verstandsstaat, en individuen zijn vrome atomen geworden (Zwart 1993, pp. 117 e.v.). Anders gezegd: ook het filosofische treuren lijkt de gewaarwording van een incongruentie te behelzen. Er is niets meer in de werkelijkheid wat met bepaalde, onontbeerlijke filosofische grondbegrippen - 'God', 'mens', 'staat', 'gemeenschap' et cetera - correspondeert. In de wijze waarop wij over telos, vriendschap, wijsheid en dergelijke spreken, manifesteert zich de deerniswekkende verbastering van de oorspronkelijke betekenis die deze begrippen ooit gehad hebben.

Een ander actueel voorbeeld van filosofische melancholie vormt wellicht het boek Hoe overleven we de vrijheid? van Herman De Dijn (1993). In de hedendaagse werkelijkheid, aldus De Dijn, lijkt een houding van overgave en vertrouwen nauwelijks nog mogelijk te zijn. Vertrouwen veronderstelt dat men zich laat inschakelen en inbedden in een groter, reeds aanwezig, betekenisvol geheel, een netwerk van relaties waarbinnen het leven betekenis krijgt. Precies dit betekenisvolle geheel is in de actuele werkelijkheid afwezig. De werkelijkheid is rusteloos, betekenisloos en leeg geworden. Een diepe maar diffuse ontevredenheid resteert. 


\section{Slot}

Structureel beschouwd kunnen lachen en treuren als elkaars inverse worden aangemerkt. Dit vooronderstelt om te beginnen dat beide fenomenen een aantal structurele kenmerken met elkaar delen.

In beide gevallen gaat het om de gewaarwording van een structurele incongruentie, een structureel tekort in een actueel, gevestigd discours. Van belang daarbij is dat filosofisch lachen of treuren niet op afzonderlijke taaluitingen betrekking heeft, maar op het type discours dat dergelijke taaluitingen genereert (cf. Zwart 1996). Weliswaar kunnen afzonderlijke taaluitingen op zichzelf als komisch of betreurenswaardig worden ervaren, maar dan als representanten van iets algemeners. Het filosofische lachen of treuren in eigenlijke zin, dat wil zeggen als filosofische stemming, heeft betrekking op het betreffende discours in zijn geheel. Het betreffende discours in zijn geheel blijkt op niets te berusten, blijkt op te gaan in niets. Daarin berust ook het verschil tussen kritiseren enerzijds en lachen of treuren anderzijds. Afzonderlijke taaluitingen kunnen we (vanuit de eigen criteria van het discours in kwestie) bekritiseren, maar bij lachen of treuren is het betreffende discours in zijn geheel in het geding. Het lachen of treuren laat het discours in zijn geheel als lachwekkend of betreurenswaardig verschijnen. Nog anders gezegd, om een bepaald discours in zijn geheel te kunnen bekritiseren, moet eerst de lachwekkendheid of betreurens waardigheid ervan tevoorschijn treden - en daartoe hebben wij filosofische blij- of treurspelers van het slag Diogenes van node.

Niettemin verschilt het filosofische lachen grondig van het filosofische treuren. Het lachen wijst op het grondige tekort van een ogenschijnlijk intact en betekenisvol discours en schept daarmee ruimte voor een toekomstig, betekenisvol spreken. Het onthult de grondige ontoereikendheid van actuele begrippelijke bepalingen van filosofische grondtermen zoals 'mens', 'God', 'gemeenschap', et cetera om op deze wijze uitzicht te verschaffen op meer geëigende begrippelijke mogelijkheden. Het treuren onthult eveneens het tekort van een actueel discours, maar dan vanuit de (denkbeeldige) herinnering aan een intact en betekenisvol spreken dat ooit verloren moet zijn gegaan. Het actuele spreken herinnert ons in dit geval aan iets dat er niet langer is. En vergeleken bij datgene wat er niet langer is, valt het actuele spreken in het niet. Het treuren onthult de grondige ontoereikendheid van het actuele spreken over 'mens', 'God', 'gemeenschap' et cetera vanuit de herinnering aan geëigende begrippelijke bepalingen die als mogelijkheid niet langer gegeven zijn. Vandaar dat MacIntyre en andere melancholische auteurs telkens in begrippelijke paren spreken: praktijk versus institutie, overgave versus beheersing, vertrouwen versus zelfbeschikking, conversatie versus communicatie et cetera. Het tweede begrip van ieder paar gaat onder een onherstelbaar betekenisverlies gebukt.

\section{Noot}

1. Dit artikel is een bewerkte versie van mijn voordracht Lachen en treuren in de filosofie. Studium Generale, Technische Universiteit Twente, 28 oktober 1997.

\section{Literatuur}

H. DE DiJn (1993) Hoe overleven we de vrijheid? Modernisme, postmodernisme en het mystiek lichaam. Kapellen, Pelckmans; Kampen, Kok Agora.

Diogenes LAerTiUs (1925/1979) Lives of eminent philosophers, Vol. 2 (Book 6 - 10) [Loeb ed.]. Cambridge, Harvard University Press - London, Heinemann. 
M. Foucault (1989) Parresia. Vrijmoedig spreken en waarheid. Amsterdam, Stichting voor filosofisch onderzoek/Krisis.

S. FreUd (1916/1946) 'Trauer und Melancholie' in Gesammelte Werke X, p. 428-446. London, Imago; Frankfurt am Main, Fischer.

G.W.F. HEGEL (1970) Werke 9: 'Enzyklopädie der philosophischen Wissenschaften im Grundrisse' (1830). Zweiter Teil: 'Die Naturphilosophie mit den mündlichen Zusätzen'. Frankfurt am Main, Suhrkamp.

Het Instituut voor Gezondheidsethiek. Maastricht, IGE; Amsterdam, Ploegsma.

I. KANT (1974) Kritik der Urteilskraft. Frankfurt am Main, Suhrkamp.

A. MACInTyRe (1984) After virtue (2e druk). Notre Dame, University of Notre Dame Press.

F. NIETZSCHE (1980) 'Die fröhliche Wissenschaft' in Sämtliche Werke 3. München/Berlin/New York, De Gruyter.

A. SCHOPENHAUER (1977) Die Welt als Wille und Vorstellung I. Zürich, Diogenes.

H. ZWART (1993) Ethische consensus in een pluralistische samenleving. De gezondheidsethiek als casus. Amsterdam, Thesis Publishers.

H. ZWART (1996) Ethical consensus and the truth of laughter: The structure of moral transformations. (Morality and the meaning of life). Kampen, Kok Pharos. 